\title{
RESEARCH
}

Open Access

\section{Effect of endoscopic resection on short- term surgical outcomes of subsequent laparoscopic gastrectomy: a meta-analysis}

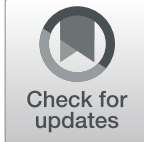

Dong Peng, Yu-Xi Cheng and Gang Liao* (D)

\begin{abstract}
Background: Endoscopic resection (ER) might affect subsequent laparoscopic gastrectomy (LG) because of the electrical coagulation, but the effect remains controversial. The purpose of this meta-analysis was to analyze the effect of ER on the short-term surgical outcomes of subsequent $L G$.

Materials and methods: The PubMed, EMBASE, and Cochrane Library databases were searched to find eligible studies published from inception to March 21, 2021. Short-term surgical outcomes were compared between the ERLG group and the LG-only group. The registration ID of this current meta-analysis on PROSPERO is CRD42021238031.

Results: Nine studies involving 3611 patients were included in this meta-analysis. The LG-only group had a higher $T$ stage (T1-T2: $\mathrm{OR}=2.42,95 \% \mathrm{Cl}=1.09$ to $5.34, P=0.03 ; \mathrm{T} 3-\mathrm{T} 4$ : $\mathrm{OR}=0.41,95 \% \mathrm{Cl}=0.19$ to $0.91, P=0.03$ ) than the ER-LG group. The ER-LG group showed a shorter operation time than the LG-only group ( $M D=-5.98,95 \% \mathrm{Cl}=-10.99$ to $-0.97, P=0.02$ ). However, no difference was found in operation time after subgroup analysis of propensity score matching studies. No significant difference was found in intraoperative blood loss, time to first oral feeding, or postoperative hospital stay between the ER-LG group and the LG-only group. And no significance was found in overall complications ( $\mathrm{OR}=1.16,95 \% \mathrm{Cl}=0.89$ to $1.50, P=0.27)$, complications of grade $\geq \| \mathrm{O}(\mathrm{OR}=1.11,95 \% \mathrm{Cl}=0.71$ to 1.73, $P=0.64)$, complications of grade $\geq \mathrm{III} b(\mathrm{OR}=1.47,95 \% \mathrm{Cl}=0.49$ to $4.43, P=0.49)$ between the ER-LG group and the LG-only group.
\end{abstract}

Conclusions: ER did not affect subsequent LG in terms of short-term outcomes, and the ER-LG group might have a shorter operation time than the LG-only group.

Keywords: Endoscopic resection, Laparoscopic gastrectomy, Gastric cancer, Meta-analysis

\footnotetext{
* Correspondence: chengduliaogang@hotmail.com

Dong Peng and Yu-Xi Cheng are co-first authors.

Department of Gastrointestinal Surgery, The First Affiliated Hospital of

Chongqing Medical University, Chongqing 400016, China
}

(c) The Author(s). 2021 Open Access This article is licensed under a Creative Commons Attribution 4.0 International License, which permits use, sharing, adaptation, distribution and reproduction in any medium or format, as long as you give appropriate credit to the original author(s) and the source, provide a link to the Creative Commons licence, and indicate if changes were made. The images or other third party material in this article are included in the article's Creative Commons licence, unless indicated otherwise in a credit line to the material. If material is not included in the article's Creative Commons licence and your intended use is not permitted by statutory regulation or exceeds the permitted use, you will need to obtain permission directly from the copyright holder. To view a copy of this licence, visit http://creativecommons.org/licenses/by/4.0/ The Creative Commons Public Domain Dedication waiver (http://creativecommons.org/publicdomain/zero/1.0/) applies to the data made available in this article, unless otherwise stated in a credit line to the data. 


\section{Introduction}

Gastric cancer is one of the most common gastrointestinal tumors worldwide [1, 2]. Early gastric cancer is defined as tumors confined to the mucosa or submucosa, and some of them can be cured by endoscopic resection (ER) [3, 4]. ER, including endoscopic submucosal dissection (ESD) and endoscopic mucosal resection (EMR), may be another option for the treatment of early gastric cancer without lymph node metastasis due to its quick recovery time and low cost $[5,6]$. However, ER-related electrocoagulation can cause large iatrogenic ulcers, which will take 4-8 weeks to completely heal. Moreover, ER may cause edema, fibrosis, and even adhesions of the stomach and the surrounding tissues, which may increase the surgical difficulty of subsequent gastrectomy [7].

Open gastrectomy has been the main method of gastric cancer for a long time. It was not until 1994 that Kitano first described the efficacy of laparoscopic gastrectomy (LG) in early gastric cancer [8]. Furthermore, LG has had rapid development and popularity due to the minimal invasion, less blood loss, less need for painkillers, and a faster recovery over the past few decades [9]. LG is an acceptable treatment option for gastric cancer, and has better short-term effects and similar longterm oncological effects, especially for early gastric cancer [10-12].

ER might affect subsequent LG because of the electrical coagulation, and previous studies on its effect on LG remain controversial [13-16]. The main purpose of this meta-analysis was to analyze the effect of ER on short-term surgical outcomes after subsequent LG, including postoperative hospital stay, time to first oral feeding, complications, intraoperative blood loss, retrieved lymph nodes, and metastatic lymph nodes of subsequent LG.

\section{Materials and methods}

The current meta-analysis followed the Preferred Reporting Items for Systematic Reviews and Meta-Analyses (PRIS MA) statement [17]. The registration ID of this current meta-analysis on PROSPERO is CRD42021238031, and the link is https://www.crd.york.ac.uk/prospero/display_record. php?ID=CRD42021238031.

\section{Literature search}

PubMed, EMBASE, and the Cochrane Library database were searched by two authors independently through March 21, 2021. The search strategy was performed with the following items: ("endoscopic resection" OR "endoscopic submucosal dissection" OR "endoscopic mucosal resection") AND ("laparoscopic gastrectomy" OR "laparoscopy-assisted gastrectomy") AND ("gastric cancer" OR "gastric carcinoma" OR "gastric neoplasms" OR "stomach cancer" OR "stomach carcinoma" OR "stomach neoplasms"). The publication language had no limitations in this search.

\section{Inclusion and exclusion criteria}

The inclusion criteria for this meta-analysis were as follows: 1, studies comparing the effect of the ER-LG group and LG-only group on laparoscopic surgery for gastric cancer; and 2, studies reporting at least one short-term outcome: intraoperative blood loss, operative time, total number of retrieved lymph nodes, the metastatic lymph nodes, postoperative complications, and postoperative hospital stay. The exclusion criteria were as follows: 1, studies were case reports, reviews, letters, conferences, or comments; and 2, publications with insufficient data that could not be extracted. For studies with overlapping patient groups, the most recent or those with larger sample sizes were included. All disagreements about inclusion were solved by group discussion.

\section{Study selection}

Two authors searched the databases independently. The title and abstract of the articles were screened for relevance first, and the full texts were then evaluated according to the inclusion and exclusion criteria. All disputes were resolved through internal discussion, and if the two authors had disagreed, the third author made a final judgment.

\section{Data extraction}

The data from the included literature were extracted by two authors respectively. The contents extracted were as follows: first author, publication year, study date, country, baseline information, surgical methods, reconstruction methods, intraoperative blood loss, operation time, total number of retrieved lymph nodes, the metastatic lymph nodes, conversion to open surgery, postoperative complications, and postoperative hospital stay. When the two authors could not reach an agreement, it was determined by a third author.

\section{Postoperative complications}

The severity of postoperative complications in this metaanalysis was performed by the Clavien-Dindo classification [18]. According to this classification, grade $\geq$ II required at least a pharmacological treatment with drugs and grade $\geq$ III b requires at least a surgical or endoscopic intervention under general anesthesia [18]. Beyond that, the specific complications including anastomotic leakage, anastomotic stenosis, intestinal obstruction, abdominal infection, gastric stasis, wound infection, pancreatic leakage, post-operative bleeding, and shortterm death were extracted as well. 


\section{Outcomes}

The primary outcome of the current meta-analysis was the postoperative complications. Secondary outcomes included intraoperative blood loss, operation time, total number of retrieved lymph nodes, the metastatic lymph nodes, time to first oral feeding, conversion to open surgery, and postoperative hospital stay.

\section{Quality assessment}

The Newcastle-Ottawa Scale (NOS) was used to evaluate the quality of the included studies. The nonrandomized studies were judged from three perspectives: selection of study comparisons, comparability between groups, and the determination of results [19].

\section{Statistical analysis}

In the meta-analysis, continuous variables are presented as the mean and standard deviation (SD), and dichotomous variables are presented as proportions. For dichotomous and continuous variables, odds ratios (ORs) and mean differences (MDs) were calculated, respectively, and $95 \%$ confidence intervals (CI) were calculated. The value of $I^{2}$ and the results of the chi-squared test were used to assess the statistical heterogeneity [20, 21]. High heterogeneity was considered when $I^{2}>50 \%$, the random effects model was used, and $P<0.1$ was considered statistically significant. The fixed effects model was used for the studies with $I^{2} \leq 50 \%$, and $P<0.05$ was considered statistically significant. This meta-analysis was performed with RevMan 5.3 (The Cochrane Collaboration, London, UK).

\section{Results \\ Study selection}

A total of 2312 studies (1130 studies in PubMed, 1129 studies in Embase, and 53 studies in the Cochrane Library) were screened in this meta-analysis. There were 2020 studies after removing the duplications. The title and abstract were screened by two authors independently, and 19 studies were evaluated at the full-text level. Case reports, reviews, letters, conferences, and comments were excluded. Finally, 9 studies [13-16, 22-26] that compared an effect of ER-LG group and LG-only group after laparoscopic surgery for gastric cancer were included in this meta-analysis (Fig. 1).

\section{Patient characteristics and quality assessment of the included studies}

There were 595 patients who underwent laparoscopic gastrectomy after ER and 3016 patients who only underwent laparoscopic gastrectomy in the 9 studies. The publication year of the 9 studies were from 2012 to 2020 , and all of the studies were retrospective studies. Seven studies were from Japan, and 2 studies were from Korea. The grade of complications and the scores of the Newcastle-Ottawa Scale of each study are shown in Table 1.
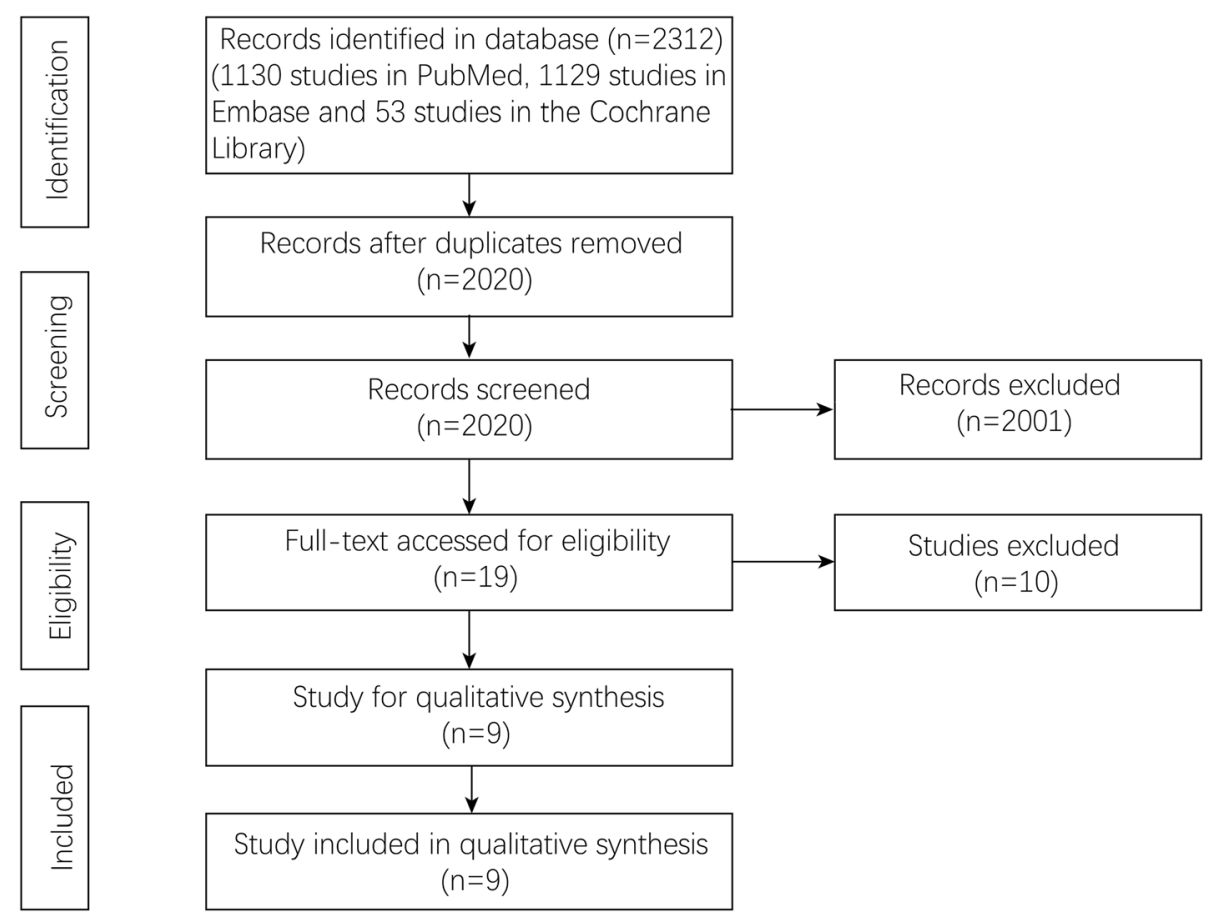

Fig. 1 Flowchart of study selection 
Table 1 Characteristics of the studies included in the meta-analysis

\begin{tabular}{|c|c|c|c|c|c|c|c|c|c|}
\hline \multirow[t]{2}{*}{ Author } & \multirow[t]{2}{*}{$\begin{array}{l}\text { Year } \\
\text { published }\end{array}$} & \multirow[t]{2}{*}{ Country } & \multirow[t]{2}{*}{$\begin{array}{l}\text { Study } \\
\text { design }\end{array}$} & \multirow[t]{2}{*}{$\begin{array}{l}\text { Study } \\
\text { date }\end{array}$} & \multicolumn{2}{|l|}{ Sample size } & \multicolumn{2}{|c|}{$\begin{array}{l}\text { Postoperative complications Clavien- } \\
\text { Dindo classification (I/II/III/IV/V) }\end{array}$} & \multirow[t]{2}{*}{ NOS } \\
\hline & & & & & ER-LG group & LG-only group & ER-LG group & LG-only group & \\
\hline Ebihara Y & 2015 & Japan & Retrospective & $2006-2013$ & 38 & 38 & $\|/\| I \|$ & $\|/\| I \|$ & 8 \\
\hline Lee EG & 2017 & Korea & Retrospective & 2003-2013 & 199 & 1505 & I/II/III/IVN & |/II/III/IVN & 8 \\
\hline Lee $\mathrm{H}$ & 2019 & Korea & Retrospective & 2013-2018 & 107 & 428 & Unknown & Unknown & 8 \\
\hline Tsujimoto H & 2012 & Japan & Retrospective & $2008-2010$ & 17 & 80 & Unknown & Unknown & 7 \\
\hline Shindo K & 2020 & Japan & Retrospective & $2000-2014$ & 47 & 94 & III/IVN & III/IVN & 7 \\
\hline Komatsu S & 2013 & Japan & Retrospective & $2007-2011$ & 30 & 172 & Unknown & Unknown & 7 \\
\hline Aoyama J & 2020 & Japan & Retrospective & 2013-2018 & 21 & 21 & II/II/IVN & II/III/VN & 8 \\
\hline Jiang $X$ & 2012 & Japan & Retrospective & 2006-2009 & 111 & 600 & Unknown & Unknown & 8 \\
\hline Suzuki T & 2013 & Japan & Retrospective & $2000-2010$ & 25 & 78 & Unknown & Unknown & 7 \\
\hline
\end{tabular}

Abbreviations: ER endoscopic resection, LG laparoscopic gastrectomy, NOS Newcastle-Ottawa Scale

\section{Baseline information}

Baseline information, including age, sex, body mass index (BMI), tumor size, comorbidity, tumor depth, American Society of Anesthesiologists (ASA) score, and degree of pathological differentiation was extracted. After pooling all of the data, the ER-LG group had a younger age $(\mathrm{MD}=4.08,95 \% \mathrm{CI}=2.10$ to $6.07, P<0.0001)$, more males $(\mathrm{OR}=1.51,95 \% \mathrm{CI}=1.23$ to $1.85, P<0.0001)$, lower comorbidity $(\mathrm{OR}=1.76,95 \% \mathrm{CI}=1.23$ to $2.51, P=$ $0.002)$, a smaller tumor size (MD $=-0.77,95 \% \mathrm{CI}=-1.00$ to $-0.55, P<0.00001)$ and a lower $\mathrm{T}$ stage $(\mathrm{T} 1-\mathrm{T} 2: \mathrm{OR}=$ $2.42,95 \% \mathrm{CI}=1.09$ to $5.34, P=0.03$; T3-T4: $\mathrm{OR}=0.41,95 \%$ $\mathrm{CI}=0.19$ to $0.91, P=0.03)$ than the LG-only group. However, no difference was found in terms of BMI (MD= $0.08,95 \% \mathrm{CI}=-0.21$ to $0.37, P=0.58$ ), ASA score (ASA1: $\mathrm{OR}=1.00,95 \% \mathrm{CI}=0.56$ to $1.77, P=1.00$; ASA2: $\mathrm{OR}=1.03$, $95 \% \mathrm{CI}=0.59$ to $1.80, P=0.92$ ) or degree of pathological differentiation (undifferentiated: $\mathrm{OR}=0.28,95 \% \mathrm{CI}=0.07$ to $1.18, P=0.08$; differentiated: $\mathrm{OR}=3.52,95 \% \mathrm{CI}=0.85$ to 14.60, $P=0.08$ ) (Table 2).

\section{Surgical methods and reconstruction methods}

The surgical methods were divided into total gastrectomy and subtotal gastrectomy, and no difference was found between the ER-LG group and the LG-only group (total gastrectomy: $\mathrm{OR}=0.94,95 \% \mathrm{CI}=0.59$ to $1.49, P=$ 0.79; subtotal gastrectomy: $\mathrm{OR}=1.07,95 \% \mathrm{CI}=0.70$ to 1.65, $P=0.75)$. Similarly, reconstruction methods were found no statistical significance in both groups as well (B-I or B-II: $\mathrm{OR}=1.09,95 \% \mathrm{CI}=0.61$ to $1.93, P=0.77$; Roux-en-Y: $\mathrm{OR}=0.93,95 \% \mathrm{CI}=0.64$ to $1.34, P=0.69$ ) (Table 2).

\section{Operation time}

Seven studies reported the operation time for laparoscopic gastrectomy, and the ER-LG group showed shorter operation time than the LG-only group ( $\mathrm{MD}=$ $-5.98,95 \% \mathrm{CI}=-10.99$ to $-0.97, P=0.02$ ) (Fig. 2).

\section{Short-term surgical outcomes}

Intraoperative blood loss, time to first oral feeding, retrieved lymph nodes, metastatic lymph nodes, postoperative hospital stay, and conversion to open surgery were extracted. No significance was found between the ERLG group and the LG-only group in terms of intraoperative blood loss $(\mathrm{MD}=-1.42,95 \% \mathrm{CI}=-22.00$ to $19.16, P=$ $0.89)$, time to first oral feeding $(\mathrm{MD}=-0.02,95 \% \mathrm{CI}=$ -0.34 to $0.31, P=0.93)$, retrieved lymph nodes $(\mathrm{MD}=$ $-2.62,95 \% \mathrm{CI}=-5.32$ to $0.07, P=0.06)$, metastatic lymph nodes $(\mathrm{MD}=0.66,95 \% \mathrm{CI}=0.43$ to $1.00, P=0.05)$, postoperative hospital stay $(\mathrm{MD}=0.54,95 \% \mathrm{CI}=-0.27$ to 1.35 , $P=0.19)$ or conversion to open surgery ( $\mathrm{OR}=0.73,95 \%$ $\mathrm{CI}=0.29$ to $1.86, P=0.51)$ (Table 2$)$.

\section{Postoperative complications}

Complications after laparoscopic gastrectomy were extracted from 9 studies. After pooling all of the data, no significance was found between the ER-LG group and the LG-only group $(\mathrm{OR}=1.16,95 \% \mathrm{CI}=0.89$ to $1.50, P=$ 0.27) (Fig. 3a). According to the Clavien-Dindo classification, grade $\geq$ II and grade $\geq$ III b were extracted separately for analysis, and no difference was found in grade $\geq$ II $(\mathrm{OR}=1.11,95 \% \mathrm{CI}=0.71$ to $1.73, P=0.64)$ or grade $\geq$ III b $(\mathrm{OR}=1.47,95 \% \mathrm{CI}=0.49$ to $4.43, P=0.49)$ between the ER-LG group and the LG-only group (Fig. $3 \mathrm{~b}$ and $\mathrm{c}$ ). Moreover, specific complications including anastomotic leakage, anastomotic stenosis, intestinal obstruction, abdominal infection, gastric stasis, wound infection, pancreatic leakage, post-operative bleeding, and short-term death were found no statistical significance between the ER-LG group and the LG-only group (Table 2). 
Table 2 Summary of characteristics between ER-LG group and LG-only group

\begin{tabular}{|c|c|c|c|c|}
\hline Characteristics & Studies & Participants (ER-LG/LG-only) & Mean difference $(95 \% \mathrm{Cl})$ & Heterogeneity \\
\hline \multicolumn{5}{|l|}{ Baseline information } \\
\hline Age, year & 7 & $540 / 2766$ & $4.08[2.10,6.07] ; P<0.0001$ & $I^{2}=71 \% ; P=0.002$ \\
\hline Male & 9 & $595 / 3016$ & $1.51[1.23,1.85] ; P<0.0001$ & $P^{2}=39 \% ; P=0.11$ \\
\hline $\mathrm{BMI}, \mathrm{kg} / \mathrm{m}^{2}$ & 8 & $570 / 2938$ & $0.08[-0.21,0.37] ; P=0.58$ & $P^{2}=0 \% ; P=0.50$ \\
\hline Tumor size, cm & 3 & $237 / 1606$ & $-0.77[-1.00,-0.55] ; P<0.00001$ & $P^{2}=0 \% ; P=0.63$ \\
\hline ASA 1 & 3 & $106 / 153$ & $1.00[0.56,1.77] ; P=1.00$ & $P^{2}=0 \% ; P=0.81$ \\
\hline ASA 2 & 3 & $106 / 153$ & $1.03[0.59,1.80] ; P=0.92$ & $P^{2}=0 \% ; P=0.87$ \\
\hline $\mathrm{T} 1-\mathrm{T} 2$ & 7 & $463 / 2510$ & $2.42[1.09,5.34] ; P=0.03$ & $P^{2}=40 \% ; P=0.13$ \\
\hline T3-T4 & 7 & $463 / 2510$ & $0.41[0.19,0.91] ; P=0.03$ & $P^{2}=40 \% ; P=0.13$ \\
\hline Pathological undifferentiated & 3 & $89 / 231$ & $0.28[0.07,1.18] ; P=0.08$ & $P^{2}=70 \% ; P=0.04$ \\
\hline Pathological differentiated & 3 & $89 / 231$ & $3.52[0.85,14.60] ; P=0.08$ & $P^{2}=70 \% ; P=0.04$ \\
\hline Comorbidity & 3 & $166 / 718$ & $1.76[1.23,2.51] ; P=0.002$ & $P^{2}=21 \% ; P=0.28$ \\
\hline \multicolumn{5}{|c|}{ Surgical methods and reconstruction methods } \\
\hline Total gastrectomy & 4 & $275 / 1644$ & $0.94[0.59,1.49] ; P=0.79$ & $P^{2}=0 \% ; P=0.86$ \\
\hline Subtotal gastrectomy & 4 & 275/1644 & $1.07[0.70,1.65] ; P=0.75$ & $P^{2}=0 \% ; P=0.86$ \\
\hline B-I or B-II & 4 & 290/1200 & $1.09[0.61,1.93] ; P=0.77$ & $P^{2}=62 \% ; P=0.05$ \\
\hline Roux-en-Y & 4 & 290/1200 & $0.93[0.64,1.34] ; P=0.69$ & $P^{2}=21 \% ; P=0.28$ \\
\hline \multicolumn{5}{|l|}{ Short-term outcomes } \\
\hline Intraoperative blood loss & 6 & $442 / 2489$ & $-1.42[-22.00,19.16] ; P=0.89$ & $P^{2}=77 \% ; P=0.0005$ \\
\hline Time to first oral feeding & 3 & $55 / 118$ & $-0.02[-0.34,0.31] ; P=0.93$ & $P^{2}=0 \% ; P=0.45$ \\
\hline Retrieved lymph nodes & 6 & $350 / 1412$ & $-2.62[-5.32,0.07] ; P=0.06$ & $P^{2}=72 \% ; P=0.003$ \\
\hline Metastatic lymph nodes & 7 & $459 / 2338$ & $0.66[0.43,1.00] ; P=0.05$ & $P^{2}=0 \% ; P=0.50$ \\
\hline Postoperative hospital stay & 6 & $442 / 2489$ & $0.54[-0.27,1.35] ; P=0.19$ & $P^{2}=0 \% ; P=1.00$ \\
\hline Conversion to open surgery & 3 & $357 / 2199$ & $0.73[0.29,1.86] ; P=0.51$ & $P^{2}=0 \% ; P=0.73$ \\
\hline \multicolumn{5}{|l|}{ Postoperative complications } \\
\hline Grade $\geq \|$ & 4 & $305 / 1658$ & $1.11[0.71,1.73] ; P=0.64$ & $P^{2}=0 \% ; P=0.69$ \\
\hline Grade $\geq \| I \mathrm{~b}$ & 3 & $284 / 1637$ & $1.47[0.49,4.43] ; P=0.49$ & $P^{2}=0 \% ; P=0.50$ \\
\hline Anastomotic leakage & 7 & $544 / 2832$ & $1.20[0.55,2.65] ; P=0.65$ & $P^{2}=0 \% ; P=0.79$ \\
\hline Anastomotic stenosis & 4 & $369 / 2049$ & $1.34[0.54,3.33] ; P=0.53$ & $P^{2}=0 \% ; P=0.66$ \\
\hline Intestinal obstruction & 7 & $522 / 2807$ & $1.70[0.93,3.13] ; P=0.08$ & $P^{2}=10 \% ; P=0.36$ \\
\hline Abdominal infection & 5 & $420 / 2315$ & $1.59[0.71,3.56] ; P=0.26$ & $P^{2}=0 \% ; P=0.65$ \\
\hline Gastric stasis & 5 & $472 / 2651$ & $0.71[0.31,1.65] ; P=0.43$ & $P^{2}=0 \% ; P=0.93$ \\
\hline Wound infection & 6 & $519 / 2745$ & $1.68[0.84,3.35] ; P=0.14$ & $P^{2}=0 \% ; P=0.90$ \\
\hline Pancreatic leakage & 5 & $328 / 1238$ & $1.25[0.53,2.94] ; P=0.62$ & $P^{2}=9 \% ; P=0.36$ \\
\hline Post-operative bleeding & 4 & $464 / 2627$ & $0.69[0.24,2.01] ; P=0.50$ & $P^{2}=0 \% ; P=1.00$ \\
\hline Short-term death & 3 & $353 / 2027$ & $2.65[0.77,9.09] ; P=0.12$ & $P^{2}=0 \% ; P=0.88$ \\
\hline
\end{tabular}

Abbreviations: $E R$ endoscopic resection, $L G$ laparoscopic gastrectomy, ASA American Society of Anesthesiologists, postoperative complications (grade $\geq$ II and grade $\geq$ III b) were graded by the Clavien-Dindo classification

Subgroup analysis of propensity score matching and nonpropensity score matching studies

The subgroup analysis was performed between propensity score matching (PS) and non-propensity score matching (non-PS) studies. In baseline information of non-PS studies, the ER-LG group had more males $(\mathrm{OR}=$ $1.83,95 \% \mathrm{CI}=1.43$ to $2.34, P<0.01)$ and younger age
( $\mathrm{MD}=6.21,95 \% \mathrm{CI}=4.24$ to $8.19, P<0.01)$ than the LGonly studies. And in baseline information of PS studies, the ER-LG group had younger age $(\mathrm{MD}=2.66,95 \% \mathrm{CI}=$ 0.96 to $4.36, P=0.002$ ) than the LG-only group. In terms of short-term outcomes of non-PS studies, the ER-LG group had less retrieved lymph nodes $(\mathrm{MD}=-3.14,95 \%$ $\mathrm{CI}=-5.01$ to $-1.27, P=0.001)$ and less metastatic lymph 


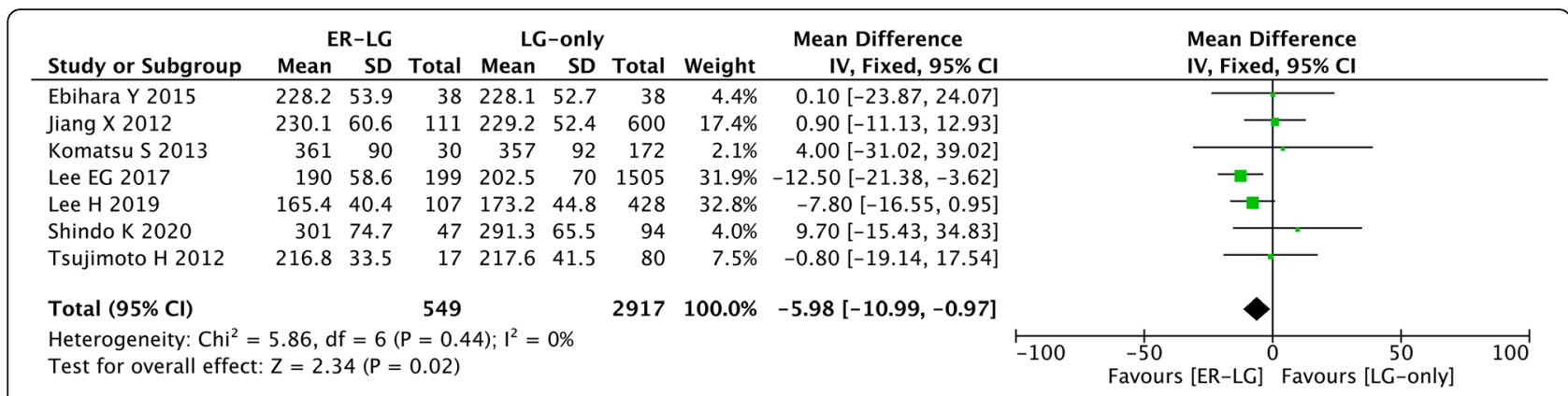

Fig. 2 Forest plot of the operation time. 95\% Cl, 95\% confidence interval; ER, endoscopic resection; LG, laparoscopic gastrectomy

nodes $(\mathrm{MD}=0.52,95 \% \mathrm{CI}=0.30$ to $0.92, P=0.02)$ than the LG-only group. No difference was found in operation time or complications of the PS studies (Table 3).

\section{Sensitivity, consistency, $I^{2}$, and publication bias}

Repeated meta-analyses were performed by excluding one study in turn as a sensitivity analysis was performed to evaluate the impact of each individual study on the pooled $\mathrm{OR}$ or MD, and the results were found to be the same. Consistency was measured by estimating the degree of inconsistency among the results of the studies.
Publication bias for the included studies was based on a visual inspection of the funnel plots, which were symmetrical, and no obvious publication bias was found (Fig. 4).

\section{Discussion}

Nine studies were included in this meta-analysis. Tumor $\mathrm{T}$ stage, surgical methods, reconstruction methods, intraoperative blood loss, operation time, the total number of retrieved lymph nodes, the metastatic lymph nodes, conversion to open surgery, postoperative complications,

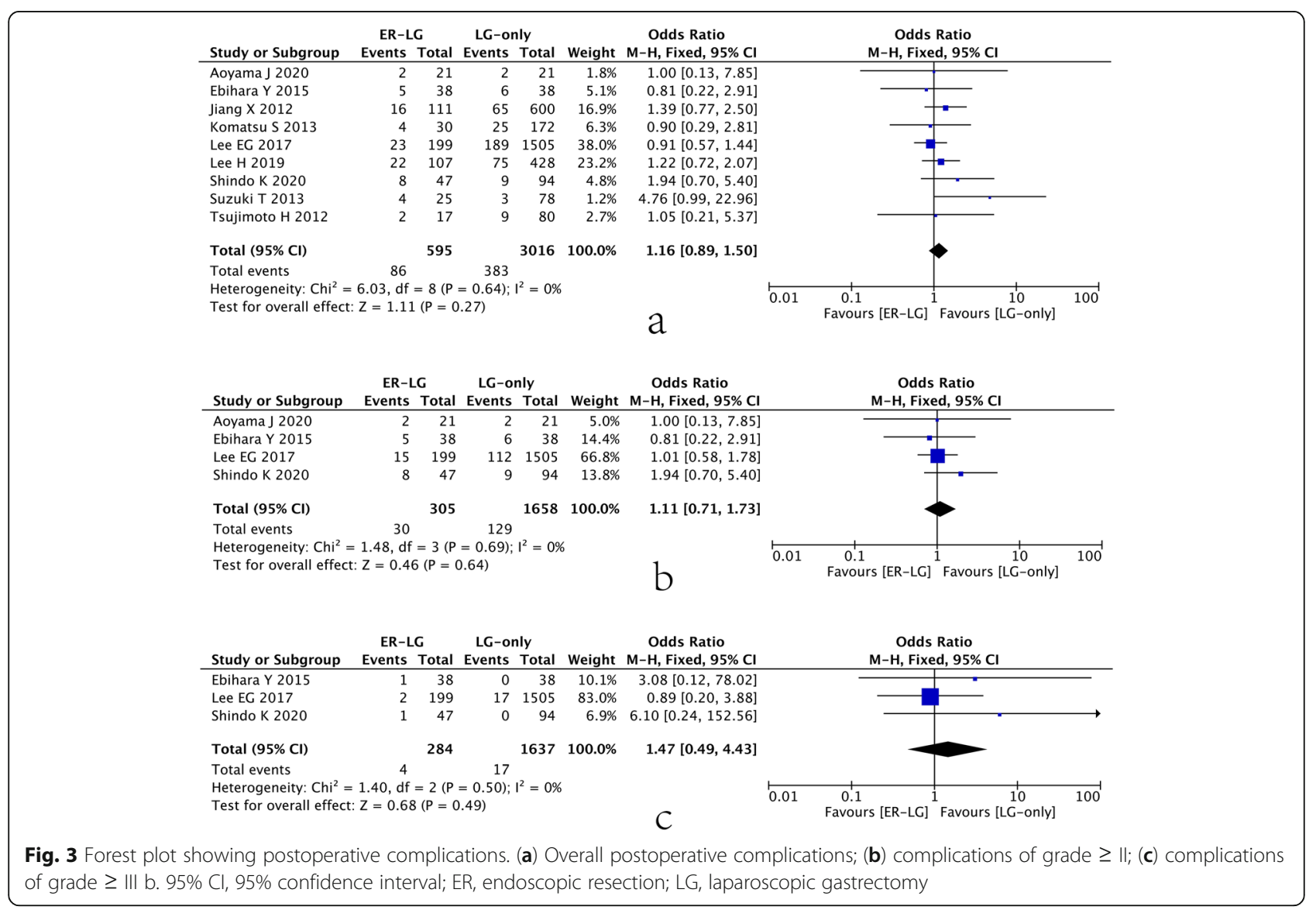


Table 3 Summary of characteristics in PS and non-PS studies

\begin{tabular}{|c|c|c|c|}
\hline \multirow[t]{2}{*}{ Characteristics } & \multicolumn{3}{|c|}{ PS/non-PS } \\
\hline & Studies & Mean difference $(95 \% \mathrm{Cl})$ & Heterogeneity \\
\hline \multicolumn{4}{|l|}{ Baseline information } \\
\hline Male & $4 / 5$ & $0.94[0.65,1.35] ; P=0.73 / 1.83[1.43,2.34] ; P<0.01$ & $P^{2}=0 \% ; P=0.91 / I^{2}=13 \% ; P=0.33$ \\
\hline Age & $4 / 3$ & $2.66[0.96,4.36] ; P=0.002 / 6.21[4.24,8.19] ; P<0.01$ & $P^{2}=25 \% ; P=0.26 / P^{2}=57 \% ; P=0.10$ \\
\hline BMI & $4 / 4$ & $-0.13[-0.60,0.34] ; P=0.58 / 0.21[-0.16,0.58] ; P=0.26$ & $P^{2}=0 \% ; P=0.98 / I^{2}=38 \% ; P=0.18$ \\
\hline $\mathrm{T} 1-\mathrm{T} 2$ & $3 / 4$ & $2.04[0.40,10.28] ; P=0.39 / 1.79[0.30,10.74] ; P=0.53$ & $P^{2}=0 \% ; P=0.49 / I^{2}=65 \% ; P=0.04$ \\
\hline T3-T4 & $3 / 4$ & $0.49[0.10,2.48] ; P=0.39 / 0.56[0.09,3.37] ; P=0.53$ & $P^{2}=0 \% ; P=0.49 / I^{2}=65 \% ; P=0.04$ \\
\hline \multicolumn{4}{|c|}{ Surgical methods and reconstruction methods } \\
\hline TG & $2 / 2$ & $1.56[0.42,5.88] ; P=0.51 / 0.87[0.53,1.44] ; P=0.60$ & $P^{2}=0 \% ; P=0.98 / I^{2}=0 \% ; P=0.72$ \\
\hline SG & $2 / 2$ & $0.64[0.17,2.41] ; P=0.51 / 1.14[0.72,1.80] ; P=0.58$ & $P^{2}=0 \% ; P=0.98 / I^{2}=0 \% ; P=0.73$ \\
\hline B-I or B-II & $2 / 2$ & $0.91[0.55,1.52] ; P=0.72 / 1.13[0.31,4.09] ; P=0.85$ & $P^{2}=0 \% ; P=0.84 / I^{2}=77 \% ; P=0.04$ \\
\hline Roux-en-Y & $2 / 2$ & $1.10[0.66,1.83] ; P=0.72 / 0.96[0.30,3.04] ; P=0.94$ & $P^{2}=0 \% ; P=0.84 / I^{2}=67 \% ; P=0.08$ \\
\hline \multicolumn{4}{|l|}{ Short-term outcomes } \\
\hline Blood loss & $2 / 4$ & $12.97[-60.39,86.34] ; P=0.73 /-6.44[-17.08,4.20] ; P=0.24$ & $P^{2}=91 \% ; P=0.0007 / R^{2}=11 \% ; P=0.34$ \\
\hline Operation time & $3 / 4$ & $-5.27[-13.08,2.55] ; P=0.19 /-6.48[-13.02,0.06] ; P=0.05$ & $P^{2}=0 \% ; P=0.39 / I^{2}=24 \% ; P=0.27$ \\
\hline Retrieved LNs & $3 / 3$ & $-2.33[-7.87,3.21] ; P=0.41 /-3.14[-5.01,-1.27] ; P=0.001$ & $P^{2}=82 \% ; P=0.004 / P^{2}=0 \% ; P=0.70$ \\
\hline Metastatic LNs & $4 / 3$ & $0.96[0.50,1.81] ; P=0.89 / 0.52[0.30,0.92] ; P=0.02$ & $P^{2}=0 \% ; P=0.62 / I^{2}=12 \% ; P=0.32$ \\
\hline PHS & $2 / 4$ & $0.60[-1.25,2.45] ; P=0.52 / 0.53[-0.37,1.43] ; P=0.25$ & $P^{2}=0 \% ; P=1.00 / P^{2}=0 \% ; P=0.95$ \\
\hline \multicolumn{4}{|c|}{ Postoperative complications } \\
\hline Overall & $4 / 5$ & $1.25[0.81,1.92] ; P=0.32 / 1.11[0.80,1.54] ; P=0.53$ & $P^{2}=0 \% ; P=0.75 / I^{2}=15 \% ; P=0.32$ \\
\hline$A L$ & $3 / 4$ & $1.18[0.22,6.28] ; P=0.84 / 1.21[0.49,2.97] ; P=0.68$ & $P^{2}=0 \% ; P=0.77 / P^{2}=0 \% ; P=0.45$ \\
\hline AS & $2 / 2$ & $2.27[0.59,8.74] ; P=0.24 / 0.86[0.23,3.28] ; P=0.83$ & $P^{2}=0 \% ; P=0.49 / I^{2}=0 \% ; P=0.92$ \\
\hline Ileus & $2 / 5$ & $1.90[0.45,8.01] ; P=0.38 / 1.66[0.85,3.25] ; P=0.14$ & $P^{2}=0 \% ; P=0.72 / I^{2}=39 \% ; P=0.16$ \\
\hline Abdominal infection & $2 / 3$ & $0.46[0.05,4.47] ; P=0.50 / 2.06[0.87,4.87] ; P=0.10$ & $P^{2}=0 \% ; P=0.76 / P^{2}=0 \% ; P=0.61$ \\
\hline Gastric stasis & $2 / 3$ & $0.60[0.15,2.36] ; P=0.47 / 0.79[0.27,2.28] ; P=0.66$ & $P^{2}=0 \% ; P=0.38 / I^{2}=0 \% ; P=0.98$ \\
\hline Wound infection & $3 / 3$ & $2.31[0.78,6.86] ; P=0.13 / 1.33[0.53,3.36] ; P=0.55$ & $P^{2}=0 \% ; P=0.65 / I^{2}=0 \% ; P=0.96$ \\
\hline$P L$ & $3 / 2$ & $2.17[0.59,7.97] ; P=0.24 / 0.80[0.23,2.77] ; P=0.72$ & $P^{2}=0 \% ; P=0.37 / I^{2}=9 \% ; P=0.29$ \\
\hline PB & $2 / 2$ & $0.71[0.18,2.81] ; P=0.63 / 0.67[0.12,3.59] ; P=0.64$ & $P^{2}=0 \% ; P=0.96 / I^{2}=0 \% ; P=0.91$ \\
\hline
\end{tabular}

Abbreviations: $E R$ endoscopic resection, $L G$ laparoscopic gastrectomy, $P S$ propensity score matching, $T G$ total gastrectomy, SG subtotal gastrectomy, $L N s$ lymph nodes, PHS postoperative hospital stay, $A L$ anastomosis leakage, $A S$ anastomotic stenosis, $P L$ pancreatic leakage, $P B$ postoperative bleeding

and postoperative hospital stay were compared. Only the operation time was different, and the ER-LG group had a shorter operation time than the LG-only group. However, no difference was found in operation time after subgroup analysis of propensity score matching studies.

ER is a standard treatment for patients with early gastric cancer and a negligible risk of lymph node metastasis $[27,28]$. Subsequent gastrectomy is required if the tumor is resected incompletely by ER. Tumor size ( $>3$ $\mathrm{cm})$, undifferentiated tumor type, and positive horizontal margins were predictors of residual incomplete gastrectomy [4]. A previous study found that LG contributed to the effectiveness of the treatment of choice for noncurative ER compared with open gastrectomy [26].

LG is currently widely accepted nowadays. Age, obesity, tumor stage, and ASA grade are potential risk factors that affect the short-term outcomes of LG [29-31].
However, whether a previous ER has an effect on the short-term outcomes of LG remains controversial.

Intraoperative blood loss, operation time, surgical methods, reconstruction methods, total number of retrieved lymph nodes, metastatic lymph nodes, conversion to open surgery, postoperative complications, and postoperative hospital stay were not significantly different between the ER-LG group and the LG-only group in this meta-analysis. The ER-LG group had a shorter operation time than the LG-only group, and these results were reported in previous studies [13]. The results of the operation time remained unclear. In this metaanalysis, we compared the baseline information between the ER-LG group and the LG-only group. ER-LG group had a smaller tumor size and a lower $\mathrm{T}$ stage than the LG-only group, which might contribute to the shorter operation time [13]. 


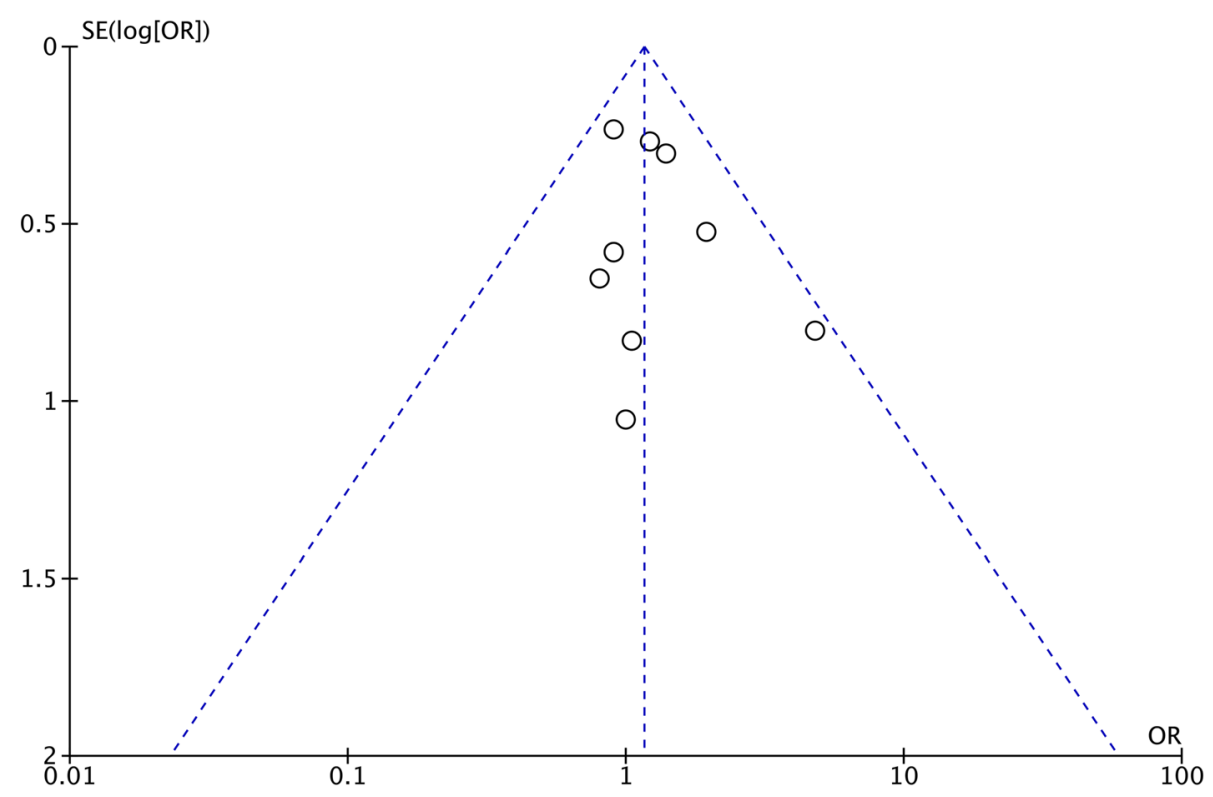

Fig. 4 Funnel plot of overall postoperative complications. SE, standard error; OR, odds ratio

In addition to the short-term outcomes of the ER-LG group and LG-only group, the previous literature mentioned some other factors that affected the subsequent LG after ER. The ER procedure can cause ulcers in the stomach, and patients can suffer from inflammation, subsequent fibrosis, and even adhesion to the outer wall of the stomach. Ulcers caused by ER reached the healing or scarring stage within 4-8 weeks [32,33]. Therefore, a shorter interval between ER and LG might cause a longer operation time and a larger amount of blood loss [23]. After ER, larger artificial ulcers $(>25 \mathrm{~mm}$ ) and intra-abdominal adhesions are usually observed, which makes additional laparoscopic gastrectomy difficult $[26,34]$. Perforation of the stomach might cause more adhesions and increase the difficulty of LG as well [14]. A previous study reported that ER affected the preservation of the celiac branch of the vagus nerve when undergoing LG, which meant that ER might have a negative impact on gastrointestinal motility [16].

The propensity score methods were performed to minimize discrepancy in clinical characteristics between the ER-LG group and LG-only group. Therefore, for more precise results, subgroup analysis of PS studies and non-PS studies were performed in this meta-analysis. However, no difference was found in operation time or complications after subgroup analysis of PS studies, and the consistent baseline information of PS studies might contribute to the results. Nevertheless, the sample size of PS studies was limited; thus, studies with PS in a large sample size should be performed in the future.

This meta-analysis had some limitations as well. First, only nine retrospective studies were involved without any cohort studies or randomized controlled trials. Second, the included studies were only from Japan and Korea; therefore, the current results applied to restricted areas. Large-scale of randomized controlled trials need to be carried out in the future. Third, the length of interval time between ER and LG was lacking, which might affect the short-term outcomes, and furthermore, the overall survival between the ER-LG group and LG-only group was not mentioned in any of the studies. Therefore, more details of ER-LG are needed in the future. In addition, the current study was a meta-analysis of retrospective studies with aggregate data (AD) rather than individual participant data (IPD). Various factors were involved in the decision of the procedure, and detailed indications for each gastrectomy option likely differ among facilities, which could be a potential source of bias. Finally, ER included ESD and EMR, and these two different methods might result in different outcomes between the ER-LG group and the LG-only group; however, previous studies did not clearly separate ESD and EMR, which needs to be done in future studies.

\section{Conclusion}

In conclusion, ER did not affect subsequent LG in terms of short-term outcomes, and the ER-LG group might have a shorter operation time than the LG-only group.

\section{Abbreviations}

ER: Endoscopic resection; LG: Laparoscopic gastrectomy; ESD: Endoscopic submucosal dissection; EMR: Endoscopic mucosal resection; BMI: Body mass index; NOS: Newcastle-Ottawa Scale; SD: Standard deviations; ORs: Odds ratios; MDs: Mean differences; Cl: Confidence intervals; ASA: American Society of Anesthesiologists; PS: Propensity score matching; AD: Aggregate data; IPD: Individual participant data 


\section{Acknowledgements}

We acknowledge all of the authors whose publications are referred in our article.

\section{Authors' contributions}

Data extraction, Dong Peng and Yu-Xi Cheng; quality assessments, Dong Peng and Gang Liao; data analysis, Dong Peng and Yu-Xi Cheng; writingorigin draft, Dong Peng; writing-review and editing, Dong Peng, Yu-Xi Cheng, and Gang Liao. All authors read and approved the final manuscript.

\section{Funding}

Sponsored by Natural Science Foundation of Chongqing, China, cstc2020jcyjmsxmX0270.

\section{Availability of data and materials}

All data generated or analyzed during this study are included in this published article.

\section{Declarations}

\section{Ethics approval and consent to participate}

Not applicable.

\section{Consent for publication}

Not applicable.

\section{Competing interests}

The authors declare that they have no competing interests.

\section{Received: 12 October 2020 Accepted: 3 April 2021}

\section{Published online: 14 April 2021}

\section{References}

1. Kamangar F, Dores GM, Anderson WF. Patterns of cancer incidence, mortality, and prevalence across five continents: defining priorities to reduce cancer disparities in different geographic regions of the world. J. Clin. Oncol. 2006;24(14):2137-50. https://doi.org/10.1200/JCO.2005.05.2308.

2. Ferlay J, Steliarova FE, Lortet TJ, et al. Cancer incidence and mortality patterns in Europe: estimates for 40 countries in 2012. Eur. J. Cancer. 2013; 49(6):1374-403. https://doi.org/10.1016/j.ejca.2012.12.027.

3. Saragoni L, Morgagni P, Gardini A, Marfisi C, Vittimberga G, Garcea D, et al. Early gastric cancer: diagnosis, staging, and clinical impact. Evaluation of 530 patients. New elements for an updated definition and classification. Gastric Cancer. 2013;16(4):549-54. https://doi.org/10.1007/s10120-013-0233-2.

4. Nie RC, Yuan SQ, Li YF, Chen S, Chen YM, Chen XJ, et al. Additional gastrectomy in early-stage gastric cancer after non-curative endoscopic resection: a meta-analysis. Gastroenterol Rep (Oxf). 2019;7(2):91-7. https:// doi.org/10.1093/gastro/goz007.

5. Tsujitani S, Oka S, Saito H, Kondo A, Ikeguchi M, Maeta M, et al. Less invasive surgery for early gastric cancer based on the low probability of lymph node metastasis. Surgery. 1999;125(2):148-54. https://doi.org/10.1016/S00396060(99)70258-8.

6. Soetikno R, Kaltenbach T, Yeh R, Gotoda T. Endoscopic mucosal resection for early cancers of the upper gastrointestinal tract. J. Clin. Oncol. 2005; 23(20):4490-8. https://doi.org/10.1200/JCO.2005.19.935.

7. Cha JH, Kim JH, Kim H, et al. The optimal timing of additional surgery after non-curative endoscopic resection to treat early gastric cancer: long-term follow-up study. Sci Rep. 2019;9(1):18331. https://doi.org/10.1038/s41598-01 9-54778-8.

8. Kitano S, Iso Y, Moriyama M, Sugimachi K. Laparoscopy-assisted Billroth I gastrectomy. Surg Laparosc Endosc. 1994;4(2):146-8.

9. Ding J, Liao GQ, Liu HL, Liu S, Tang J. Meta-analysis of laparoscopy-assisted distal gastrectomy with D2 lymph node dissection for gastric cancer. J Surg Oncol. 2012;105(3):297-303. https://doi.org/10.1002/jso.22098.

10. Kelly K, Selby L, Chou JF, Dukleska K, Capanu M, Coit DG, et al. Laparoscopic versus open gastrectomy for gastric adenocarcinoma in the west: a case-control study. Ann. Surg. Oncol. 2015;22(11):3590-6. https://doi. org/10.1245/s10434-015-4381-y.

11. Son T, Hyung WJ. Laparoscopic gastric cancer surgery: current evidence and future perspectives. World J. Gastroenterol. 2016;22(2):727-35. https://doi. org/10.3748/wjg.v22.i2.727.
12. Hyung WJ, Yang HK, Park YK, et al; Korean Laparoendoscopic Gastrointestinal Surgery Study Group. Long-term outcomes of laparoscopic distal gastrectomy for locally advanced gastric cancer: The KLASS-02-RCT randomized clinical trial. J Clin Oncol. 2020;38(28):3304-13. https://doi.org/10.1200/JCO.20.01210.

13. Lee EG, Ryu KW, Eom BW, Yoon HM, Kim Yl, Cho SJ, et al. The effect of endoscopic resection on short-term surgical outcomes in patients with additional laparoscopic gastrectomy after non-curative resection for gastric cancer. J Gastric Cancer. 2017;17(1):33-42. https://doi.org/10.5230/jgc.2017.17.e4.

14. Komatsu S, Ichikawa D, Kubota T, Okamoto K, Shiozaki A, Fujiwara H, et al. Clinical influence of endoscopic resection on subsequent laparoscopic gastrectomy for gastric cancer. Anticancer Res. 2013;33(9):4023-8.

15. Tsujimoto $H$, Yaguchi $Y$, Kumano I, et al. Laparoscopic gastrectomy after incomplete endoscopic resection for early gastric cancer. Oncol. Rep. 2012; 28(6):2205-10. https://doi.org/10.3892/or.2012.2046.

16. Jiang X, Hiki N, Yoshiba H, Nunobe S, Kumagai K, Sano T, et al. Laparoscopyassisted gastrectomy in patients with previous endoscopic resection for early gastric cancer. Br J Surg. 2011;98(3):385-90. https://doi.org/10.1002/bjs. 7358.

17. Moher D, Liberati A, Tetzlaff J, Altman DG, The PRISMA Group. Preferred reporting items for systematic reviews and meta-analyses: the PRISMA statement. PLoS Med. 2009;6(7):e1000097. https://doi.org/10.1371/journal. pmed.1000097.

18. Dindo D, Demartines N, Clavien PA. Classification of surgical complications: a new proposal with evaluation in a cohort of 6336 patients and results of a survey. Ann Surg. 2004;240(2):205-13. https://doi.org/10.1097/01.sla.0000133 083.54934.ae.

19. Stang A. Critical evaluation of the Newcastle-Ottawa scale for the assessment of the quality of nonrandomized studies in meta-analyses. Eur J Epidemiol. 2010;25(9):603-5.

20. Ioannidis JP. Interpretation of tests of heterogeneity and bias in metaanalysis. J Eval Clin Pract. 2008;14(5):951-7. https://doi.org/10.1111/j.1365-2 753.2008.00986.x.

21. Higgins JP, Thompson SG, Deeks JJ, Altman DG. Measuring inconsistency in meta-analyses. BMJ. 2003;327(7414):557-60. https://doi.org/10.1136/bmj.327. 7414.557.

22. Shindo K, Castillo J, Ohuchida K, Moriyama T, Nagai S, Moriyama T, et al. Influence of endoscopic resection on additional laparoscopic distal gastrectomy: a propensity score-matching analysis. Surg. Today. 2020;50(10): 1290-6. https://doi.org/10.1007/s00595-020-02012-8.

23. Lee $\mathrm{H}$, Lee $\mathrm{HH}$, Song KY, Park CH, Lee J. Negative impact of endoscopic submucosal dissection on short-term surgical outcomes of subsequent laparoscopic distal gastrectomy for gastric cancer. Ann. Surg. Oncol. 2020; 27(1):313-20. https://doi.org/10.1245/s10434-019-07962-z.

24. Aoyama J, Sakuramoto S, Miyawaki Y, Ito M, Ito S, Watanabe K, et al. Impact of endoscopic resection on the choice of surgical procedure in patients with additional laparoscopic gastrectomy. Gastric Cancer. 2020;23(5):913-21. https://doi.org/10.1007/s10120-020-01057-5.

25. Ebihara Y, Okushiba S, Kurashima Y, Noji T, Nakamura T, Murakami S, et al. Totally laparoscopic gastrectomy for gastric cancer after endoscopic submucosal dissection: a propensity score matching analysis. Langenbecks Arch Surg. 2015;400(8):967-72. https://doi.org/10.1007/s00423-015-1349-0.

26. Suzuki T, Tanabe K, Vu DTA, Misumi T, Fujikuni N, Tokumoto N, et al. Safety and efficacy of laparoscopy-assisted gastrectomy after endoscopic submucosal dissection for early gastric cancer: a retrospective report. Journal of Cancer Therapy. 2013;04(1):54-60. https://doi.org/10.4236/jct.2 013.41A008.

27. Ono H, Kondo H, Gotoda T, Shirao K, Yamaguchi H, Saito D, et al. Endoscopic mucosal resection for treatment of early gastric cancer. Gut 2001;48(2):225-9. https://doi.org/10.1136/gut.48.2.225.

28. Jung $\mathrm{DH}$, Huh CW, Kim JH, Hong JH, Park JC, Lee YC, et al. Risk-stratification model based on lymph node metastasis after noncurative endoscopic resection for early gastric cancer. Ann. Surg. Oncol. 2017;24(6):1643-9. https://doi.org/10.1245/s10434-017-5791-9.

29. Min SH, Won Y, Kim G, et al. 15-year experience of laparoscopic gastrectomy in advanced gastric cancer: analysis on short-term and longterm oncologic outcome. Surg Endosc. 2020;34(11):4983-90. https://doi. org/10.1007/s00464-019-07292-X.

30. Hirahara N, Tajima Y, Fujii Y, et al. Prediction of postoperative complications and survival after laparoscopic gastrectomy using preoperative Geriatric Nutritional Risk Index in elderly gastric cancer patients. Surg Endosc. 2021; 35(3):1202-99. https://doi.org/10.1007/s00464-020-07487-7. 
31. Wang WJ, Li HT, Yu JP, Su L, Guo CA, Chen P, et al. Severity and incidence of complications assessed by the Clavien-Dindo classification following robotic and laparoscopic gastrectomy for advanced gastric cancer: a retrospective and propensity score-matched study. Surg Endosc. 2019; 33(10):3341-54. https://doi.org/10.1007/s00464-018-06624-7.

32. Tomita T, Kim Y, Yamasaki T, Okugawa T, Kondo T, Toyoshima F, et al. Prospective randomized controlled trial to compare the effects of omeprazole and famotidine in preventing delayed bleeding and promoting ulcer healing after endoscopic submucosal dissection. J Gastroenterol Hepatol. 2012;27(9):1441-6. https://doi.org/10.1111/j.1440-1746.2012.07144.x.

33. Higuchi K, Takeuchi T, Uedo N, Takeuchi Y, Naito Y, Yagi N, et al. Efficacy and safety of 1-week Helicobacter pylori eradication therapy and 7-week rebamipide treatment after endoscopic submucosal dissection of early gastric cancer in comparison with 8-week PPI standard treatment: a randomized, controlled, prospective, multicenter study. Gastric Cancer. 2015; 18(3):612-7. https://doi.org/10.1007/s10120-014-0404-9.

34. Akagi T, Shiraishi N, Hiroishi K, Etoh T, Yasuda K, Kitano S. Case series of intra-abdominal adhesions induced by artificial ulceration after endoscopic submucosal dissection before additional laparoscopic gastrectomy. Gastrointest. Endosc. 2010;72(2):438-43. https://doi.org/10.1016/j.gie.2010. 03.1066 .

\section{Publisher's Note}

Springer Nature remains neutral with regard to jurisdictional claims in published maps and institutional affiliations.

Ready to submit your research? Choose BMC and benefit from:

- fast, convenient online submission

- thorough peer review by experienced researchers in your field

- rapid publication on acceptance

- support for research data, including large and complex data types

- gold Open Access which fosters wider collaboration and increased citations

- maximum visibility for your research: over $100 \mathrm{M}$ website views per year

At BMC, research is always in progress.

Learn more biomedcentral.com/submissions 